\title{
Geoprocessamento como prática biopolítica no governo municipal
}

\author{
Cristian Caê Seemann Stassun \\ Universidade Federal de Santa Catarina \\ Kleber Prado Filho \\ Universidade Federal de Santa Catarina
}

Desde 2005 as fotos de satélite de alta resolução do "Google Earth" possibilitaram a qualquer pessoa visualizar do espaço sua cidade, bairro e casa por meio do acesso à internet. Essa tecnologia é investida há pelo menos 50 anos num tipo de processamento que integra mapas aéreos numa rede de informações organizada para gestão de cidades. O geoprocessamento é um sistema de informação geográfica que pode ser aplicado em municípios para obter informações globais de infraestrutura, saúde, educação, saneamento e criminalidade, permitindo a construção e o planejamento de políticas públicas mais eficientes. Este dispositivo biopolítico, diante do referencial em Michel Foucault, foi objeto e método de análise em uma prefeitura municipal de Santa Catarina. Seja pelo mercado de informações que se forma, pelo acesso ilimitado dos dados e do aumento da precisão das aplicações, ou ainda sobre o agenciamento de práticas de regulação das populações e de formas de subjetividade constituídas pela gestão, vigilância e governo fino das populações, o geoprocessamento como recurso de saber e poder consegue conhecer e se constituir para governar a vida dos indivíduos. Esse mesmo caminho dissertativo possibilitou gerar inteligibilidade para avaliar possibilidades de resistência ao dispositivo e perceber historicamente como esse Sistema de Informação Geográfica (SIG) consegue agregar a gestão tanto do território quanto da população.

Palavras-chave: geoprocessamento; biopolítica; dispositivo; governo; Michel Foucault.

\section{Geoprocesamiento como práctica biopolítica en lo gobierno municipal}

Desde 2005, las imágenes de satélite de alta resolución "Google Earth" permite a cualquiera ver una ciudad espacial, el barrio y el hogar a través del acceso a Internet. Esta tecnología se invierte por lo menos 50 años en una especie de proceso que integra mapas aéreos de una red de información organizada para la gestión de la ciudad. El geoprocesamiento es un sistema de información geográfica que se puede aplicar a los municipios para la infraestructura mundial de la información, la salud, la educación, el saneamiento y la delincuencia, lo que permite la construcción y la planificación de las

Artigo recebido em 2 nov. 2011 e aceito em 5 set. 2012. 
políticas públicas más eficientes. Este dispositivo biopolítico antes de la referencia a Michel Foucault, era el objeto y método de análisis en un gobierno municipal de Santa Catarina. Sé la información de mercado que se forma en datos ilimitados y aumentar la precisión de las aplicaciones, o sobre las prácticas de la agencia de regulación de las poblaciones y formas de subjetividad constituida por la gestión, supervisión y administración de las poblaciones delgadas, geoprocesamiento como un recurso de conocimiento y poder, se pueden encontrar y establecer para gobernar las vidas de las personas. Esta misma ruta habilitada dissertative generar inteligibilidad para evaluar las posibilidades de dispositivo de resistencia y darse cuenta de que, históricamente, como el Sistema de Información Geográfica (SIG) puede agregar la dirección tanto del territorio y la población.

Palabras clave: geoprocesamiento; biopolítica; dispositivo; gobierno; Michel Foucault.

\section{Geoprocessing as biopolitical practice in municipal government}

Since 2005 photos of high resolution satellite imagery of the "google earth" allowed anyone to see their space city, neighborhood and home through the internet access. This technology is invested for at least 50 years in a type of processing that integrates aerial maps a network of organized information management for cities. The geoprocessing is a geographic information system that can be applied to municipalities to obtain global information infrastructure, health, education, sanitation and crime, allowing the construction and planning of public policies more effective. This dispositive biopolitical before the reference to Michel Foucault, was the object and method of analysis in a municipal government of Santa Catarina. Be the market information that is formed by unlimited data and increase the accuracy of applications, or about agency practices for the regulation of populations and forms of subjectivity constituted by the management, monitoring and fine-government people, the geoprocessing as a resource of knowledge and power, to know and be able to govern the lives of individuals. This same path dissertational possible to generate intelligibility to evaluate possibilities of resistance to the device and see how this historically Geographic Information System can add the management of both territory and population.

KEY WORDs: geoprocessing; biopolitics; dispositive; government; Michel Foucault.

\section{Introdução}

Os novos dispositivos de segurança da atualidade estão engendrados para formar sistemas de governo das populações, produzir discursos técnico-científicos e verdades que se apresentam como maneira de conduzir ações humanas. A base dessa discussão advém do pensador francês Michel Foucault que, em um de seus últimos cursos no Collège de France chamado Segurança, território e população (2008), problematizou como a história do presente pode nos revelar dispositivos tecnológicos estratégicos construídos pelo discurso da segurança, e de que forma a entrada do Estado no campo da prática e do pensamento dos homens mudou o foco do governo, do território para as populações.

Para explicar essas novas possibilidades de gestão pública de forma concreta, essa pesquisa teve como objeto de estudo uma geotecnologia chamada Geoprocessamento, que, de acordo com Rodrigues (1988), é um sistema de coleta e tratamento de informações espaciais 
e cartográficas interpoladas com dados estatísticos, junto a um software que processa esses dados de forma gerencial. O Sistema de Informação Geográfica (SIG) permite coletar e cruzar informações para expor determinada situação das políticas públicas ou características de um município, transformando esses dados em tomada de decisão legal, administrativa e econômica, assim como para as atividades de planejamento urbano e rural, chegando a ser usado em discursos genéricos, como um "raio X" de uma cidade, mesmo que nesse teor esteja muito mais como instrumento de discurso político (Aronoff, 1989). Nesse caminho, os municípios começaram a reconhecer os benefícios potenciais de uma abordagem mais integrada aos seus dados computadorizados em geral e à organização da informação georreferenciada em particular, como ferramenta para melhor gestão e aumento da arrecadação tributária.

No contexto da individualidade, as novas geotecnologias estão presentes entre a população brasileira no século XXI de um modo mais habitual do que imaginamos. A codificação do espaço e o controle de circulação humana em um ambiente urbano podem ser mais bem evidenciados em cenas cotidianas, a exemplo, um simples deslocamento de uma pessoa hipertensa ao seu médico, da sua casa ao centro da cidade. Essa suposta pessoa acordaria e, antes mesmo de dormir, sua cidade, seu bairro, sua rua, sua casa e alguns dos seus hábitos já seriam geoprocessados por um SIG. Na área da saúde esse mesmo mecanismo mapearia pelo SIG qual a demanda de saúde do seu bairro e de acordo com a população, endemias e pactuações entre as verbas governamentais se destinaria um cardiologista especialista em tratamento de hipertensão para lhe atender na policlínica de referência. A fachada de sua casa estaria fotografada e no banco de dados da prefeitura, que tem acesso ao seu consumo de água e energia elétrica, encontraria o seu cadastro socioeconômico, seu cadastro ativo de dívidas para com o município e um "extrato" com sua necessidade de atendimento gratuito no Sistema Único de Saúde (SUS). Nesse momento, sem perceber, essa pessoa estaria acordando com uma nova identidade para a prefeitura. Um servidor municipal digita seu número e um geocódigo com todo seu perfil aparece na tela de um computador. Quando andar na rua vai ser alvejada por inúmeras propagandas sobre comida saudável, farmácias com promoções, academias de ginástica e empresas que mapearam através do seu perfil e dos seus vizinhos uma nova demanda de hipertensos iguais a ela. Essas empresas fizeram um plano de negócio usando a ferramenta chamada geomarketing, que permite calcular uma estratégia de circulação de pessoas por um raio de alcance a partir da empresa criada, sabendo de possíveis clientes circulando por aquela região antes mesmo de existir o serviço. No imaginário desta suposta pessoa estaria um discurso de proteção, pois a polícia, que tem mapeado os lugares de maior criminalidade da cidade, está lá fazendo suas rondas e nessas alturas a sua seguradora de carro já assinou a apólice de seguro em cima de um preço condizente a essa área de risco de sua circulação. A sua própria roupa foi mapeada pela empresa de cartão de crédito que vai lhe ligar oferecendo um novo modelo de produto ou de cartão de crédito para seu perfil de consumidor moderno, estressado e hipertenso. Na rua onde andou com seu carro, sua rota foi balizada e marcada pelos pontos do GPS para achar a forma mais rápida e segura para ir ao seu médico. Depois disso, seu celular é localizado pelo celular de um amigo por aplicativos de geolocalização anexos em redes sociais e ele sabe o local da cidade para encontrá-lo 
para um almoço bem gorduroso depois da consulta feita pelo médico. Por todo seu trajeto foi acompanhado por câmeras de monitoramento eletrônico, na rua ou na entrada da policlínica onde foi atendido.

O interesse por esta pesquisa se formou por questionamentos de cenas como essas, que parecem fábulas meramente ingênuas antes de constatar que são reais e atuais, instigando os leitores a pensar sobre como certas tecnologias se tornaram suporte da vida e a própria vida, um processo de espetacularização da intimidade. Nessa volta do que emerge como real, este artigo permeará a implantação de um SIG em uma cidade de 60 mil habitantes de Santa Catarina, nominada de Meteora. ${ }^{1} \mathrm{O}$ objeto de pesquisa foi o dispositivo "geoprocessamento" e a problemática segue a análise de: como essa tecnologia gera informações para práticas de governo da vida; como o dispositivo interage com o saber que potencializa; que tipo de política de verdade ele "fala" através dos instrumentos que o publicizam; qual o uso dessas informações georreferenciadas para o controle governamental e que rede de interesses econômicos o envolve, como este instrumento atinge a individualidade e a intimidade da população e sobre que argumentos e racionalidade esse dispositivo de governamentalidade se configura.

Por ser um sistema emergindo perante as tecnologias políticas que estão intimamente ligadas à vida das pessoas, problematizamos, ainda, quais os limites éticos de acesso e alcance desses dados em relação à privacidade e ao nível de invasão das informações de uma localidade, rua, casa ou cidadão. Algumas preocupações iniciais foram pelo SIG possuir uma base de dados centralizada que permite a um servidor público acessar diretamente todos os conjuntos de dados de que necessitar e permite que a informação seja integrada de uma maneira virtualmente "ilimitada".

\section{Método e objeto de pesquisa}

No momento em que a administração pública fica responsável por fazer a gestão dos meios de vida de uma população, da destinação orçamentária para políticas públicas de saúde, assistência social, segurança ou educação, existe uma ampliação da noção de poder sobre os fenômenos do homem enquanto espécie. Administrar os eventos populacionais que ocorrem em série, em massa e aleatoriamente tornou-se uma preocupação científica na Europa desde o século XVIII. Por meio da centralização das informações governamentais, acesso fino e específico ao corpo coletivo mediante previsões, estimativas, medições globais e regulações, os governos europeus tiveram uma maior eficiência para dar conta de assegurar o estado de vida nas cidades e intervir na "maneira de viver" (Foucault, 2008). Porém, a tecnologia da informação e o desenvolvimento de uma economia de dados geográficos desenvolvidos por todo mundo

\footnotetext{
${ }^{1}$ Meteora se refere a um nome fictício utilizado para representar uma cidade de 60 mil habitantes do interior de Santa Catarina. Mesmo se tratando de informações obtidas por documentos públicos, as informações envolvem assuntos estratégicos e políticos; por isso, tanto as citações, quanto as referências omitem o nome real da cidade ou substituem por Meteora.
} 
puderam ser concebidos como instrumento de governo no formato de um geoprocessamento, dando forma a um meio de gestão da população e seus vários níveis de necessidade, ao que chamamos de dispositivo.

Seja em Foucault (1987) na descrição feita do Panóptico de Bentham (2000) e das sociedades disciplinares como arquitetura de governo, ou em Deleuze (1992) pautando as sociedades de controle, o que está em jogo são formas de se exercer o poder, apoiadas em instrumentos de saber, produzindo efeitos de subjetivação e sujeição. Quando conseguimos isolar as estratégias destas relações de força que suportam tipos de saberes e vice-versa, podemos conceber, então, um dispositivo. Agamben (2005:13) afirma que "(...) dir-se-ia que hoje não haveria um só instante na vida dos indivíduos que não seja modelado, contaminado ou controlado por algum dispositivo". Prado Filho (2006) complementa que esse é um caminho de deslocamento da análise política, dos domínios do Estado para a sociedade, tal qual o resultado final de uma rede microfísica de poder de organizações, instituições, multiplicidade de relações, pequenas coerções e diversas formas de sujeição. Foucault (1979) discute que entre esses elementos, discursivos ou não, existe um tipo de jogo, ou seja, mudanças de posição, modificações de funções, certa manipulação das relações de força que de forma racional utiliza, bloqueia, estabiliza, faz seguir certas direções, numa função estratégica dominante.

Segundo Foucault (1987), além de o dispositivo ter uma função estratégica, estaria enunciando uma nova concepção política do poder em oposição a qualquer teoria de Estado, que não atuaria por repressão ou ideologia, e seus movimentos históricos seriam possíveis de visualizar a partir da genealogia. Foucault (1994) elucida que o dispositivo define o nexo do jogo que pode existir entre elementos como discursos científicos, filosóficos e morais, instituições, leis, arquiteturas, medidas administrativas, superando a dualidade entre formações discursivas (saber) e não discursivas (poder). A geotecnologia "geoprocessamento" utilizada como técnica de governo reflete um dispositivo tecnológico específico de função biopolítica que vem emergindo com certa "naturalidade" em todas as partes do mundo. Dispositivo esse, de governamentalidade e não de governo, por esse termo ser mais apropriado, ao qual Foucault refere o conjunto das ações - dispersadas, disseminadas e microfísicas do poder - que objetivam conduzir ou estruturar as ações e a palavra governo para designar tudo o que diz respeito às instâncias centralizadoras do Estado (Veiga-Neto, 2002:19).

Ao decidir utilizar o dispositivo como "método e objeto" de pesquisa, enfrentamos um vazio metodológico-conceitual evidente, pois forjamos, de acordo com o foco proposto, uma nova flexão dos modos de pesquisar em Foucault. Para dar suporte a esse caminho, usamos a arqueologia e a genealogia como base para investigação, visto que foram elas as utilizadas para analisar outros objetos que Foucault problematizou, como: o dispositivo do pan-óptico no livro Vigiar e punir, o dispositivo da sexualidade no livro História da sexualidade: vontade de saber, ou o dispositivo de segurança no livro Segurança, território e população. Usamos essas duas engrenagens sob um desafio nada fácil, que é o de construir um "método", um modo de olhar e uma forma de estabelecer os procedimentos de pesquisa com a "caixa de ferramentas" que Foucault nos oferece para analisar o objeto geoprocessamento. Isso é compreensível porque Foucault (2006) não possui uma metodologia, um campo sistemático, um roteiro prees- 
tabelecido, a não ser um instrumento, uma lógica própria de olhar as relações de poder e as lutas que se engajam em torno delas. Inegavelmente estamos dentro de uma reflexão sobre um tipo de história específica, com uma forma de pesquisar flexionada ao objeto estudado (Stassun, 2010:54-71).

Foucault (2006) declara que, no fundo, buscava as relações que existem entre poder e saber, analisando o saber em termos de região, de domínio, de implantação, de deslocamento, de transferência, apreendidos no processo pelo qual o saber funciona como um poder e reconduz seus efeitos. Para Foucault (1985:97), o caminho possível é “(...) interrogá-los nos dois níveis, o de sua produtividade tática (que efeitos recíprocos de poder e saber proporciona) e o de sua integração estratégica (que conjuntura e que correlação de forças torna necessária sua utilização em tal ou qual episódio dos diversos confrontos produzidos)". O problema de Foucault (1994:27) era saber como os homens se governam (a si mesmos e aos outros) através da produção de verdades acontecendo em conjuntos singulares de práticas, em regimes diferentes de jurisdição e verificação, no coração da análise histórica e da crítica política.

Destes enunciados, criamos uma relação de como a coleta das informações do geoprocessamento em uma localidade pode ser referenciada como importante para as políticas públicas municipais. Pesquisamos como emergiu esse dispositivo através de fontes de informação documentais de domínio público nas decisões encontradas entre 2005 e 2010 (seis anos) na forma de: discursos dos políticos, jornalistas, engenheiros, servidores públicos e empresários, por meio de atas, leis, audiências públicas, periódicos, sites, projetos, protocolos de cooperação e licitações; na Prefeitura, Câmara de Vereadores, Associação de Municípios e Empresas que oferecem o serviço e que se organizam para produção de um discurso verdadeiro para aprovação, emergência, convencimento e visibilidade do geoprocessamento para população. Esse é o eixo central da emergência desse dispositivo em Meteora.

\section{Material pesquisado: SIG na gestão pública municipal de Meteora}

Segundo a Revista Cidade do Brasil (2005), estima-se que cerca de 80\% das atividades efetuadas numa prefeitura sejam dependentes do fator localização. Do ponto de vista financeiro, a implantação do geoprocessamento e a atualização da base cadastral a ele associada trazem aumento da arrecadação. É um investimento com alta taxa de retorno para a prefeitura. Trata-se de uma tecnologia que cada vez mais amplia seu espaço de utilização, particularmente nas prefeituras, onde sua aplicação pode atingir as áreas mais diversas como: ordenamento e gestão do território, otimização de arrecadação, localização de equipamentos e serviços públicos, identificação de público-alvo de políticas públicas, gestão ambiental, gerenciamento do sistema de transportes e comunicação.

No Projeto Básico de Meteora (anexo ao Protocolo de Cooperação, 2007), os serviços resultantes do SIG servirão para tomar melhores decisões de caráter tático de planejamento, gerenciamento e alocação de recursos, destacando dois fatores: o caráter do "controle eficiente" (exatidão de dados com parâmetros científicos) e a "gestão corporativa", com integração 
das secretarias no compartilhamento de informações, ações conjuntas e agilização nos procedimentos da gestão.

O Programa TrackSourse foi a primeira ferramenta para implantação do geoprocessamento na cidade, atualizando geocódigos para fornecer imagens multifatoriais para aparelhos de GPS. De acordo com a notícia no site da Prefeitura Municipal de Meteora (2008), estas informações auxiliarão as pessoas que possuem um aparelho GPS a encontrar ruas, serviços públicos e até mesmo estabelecimentos comerciais. O sistema de navegação GPS é um incentivo às áreas de turismo de eventos e de negócios, empresarial, esportes radicais, geomarketing, desenvolvimento da área rural, medidas de emergência para as entidades como o Corpo de Bombeiros (para chegar em um bairro mais distante ou trilhas em propriedades para resgates), polícia e defesa civil. A busca de informações para o TrackSourse ajudou na localização de pontos e coordenadas que foram úteis para o Protocolo de Cooperação. Para os dados do cadastro imobiliário municipal que estavam desatualizados, montaram-se sobre a estrutura dos mapas as primeiras atualizações de novas ruas, loteamentos, condomínios e indícios de exploração ambiental.

A segunda utilidade para o geoprocessamento foi um processo de "Reestruturação do Fluxo Viário", que permitiu avaliar as condições de tráfego e de segurança de vias, as condições da superfície de rolamento destas, a durabilidade (vida útil) e o custo da manutenção anual do sistema viário. Tendo um relatório mapeado sobre o número de acidentes, causas, circulação (direção e fluxos) de veículos e pessoas, situação dos buracos, escoamento dos automóveis em horários de pico e informações alimentadas pela população, foi possível fazer um monitoramento e avaliação profunda da Rede Viária Urbana e do planejamento de destinação das verbas. O documento da Aeavi (2005) estabeleceu um roteiro de trabalho com estratégias gerais procurando o total aproveitamento da malha viária existente, a melhoria na fluidez e segurança do tráfego, a eliminação de conflitos, a elaboração de rotas específicas para ciclistas, ônibus e caminhões e a preservação dos interesses econômicos e sociais da cidade. O Geoprocessamento, além da área urbana, possibilitou alterar mapas temáticos para a caracterização da rede viária rural e subsidiar no planejamento de novas ruas, contribuindo para a manutenção da escoação da produção rural. Essa estruturação do sistema viário compreendeu junto ao plano diretor uma estratégia para garantir que a cidade tenha sustentabilidade e o crescimento organizado de acordo com a vocação econômica do município.

O terceiro impacto do projeto foi em relação ao Plano Diretor focando o controle de cheias, o setor imobiliário e a assistência social. Em Meteora nasce o rio Itajaí-Açu, o rio mais importante da bacia do Vale do Itajaí onde, no final do ano de 2008, ocorreu uma das maiores catástrofes naturais brasileiras com enchentes e deslizamentos de terra que destruíram cidades e mataram várias pessoas. "O número de mortes causadas pela chuva que atinge Santa Catarina desde o fim de semana passado já chega a 109, (...) mais de 78 mil pessoas deixaram suas casas. Pelo menos 19 permanecem desaparecidas. Ao todo, mais de 1,5 milhões de pessoas foram afetadas pelas chuvas" (G1, 2008:1). Para Carvalho e Sá (2002), o geoprocessamento pode gerar medidas fundamentais na prevenção de catástrofes ao: selecionar imóveis em áreas de probabilidade de deslizamento e classificar as áreas de risco; adotar medidas 
preventivas e corretivas; fornecer relatórios de chuvas por períodos determinados e leitura em tempo real; atender rapidamente às situações de risco; indicar ponto de socorro e abrigo mais próximo; gerenciar a comunicação de alertas aos usuários externos. No município de Meteora as primeiras atividades do SIG geraram mapas das áreas inundáveis por enchentes e referências de previsão do nível de elevação das águas do rio Itajaí-Açu com a altimetria do terreno possibilitando, já na construção do imóvel, escolher uma melhor área ou implementar mecanismos de proteção.

O Plano Diretor e o Plano de Ocupação Territorial de Meteora, que ocorreram logo depois de outras enchentes históricas (1983-84), delinearam os procedimentos de ocupação do solo e mapeamento dessas possíveis áreas de risco de inundações, refletindo diretamente na formulação de suas regras fundamentais. Na cidade de Meteora o uso que é feito do solo remete a explorar outra possibilidade de um SIG. O aumento da arrecadação através da atualização das medidas de imóveis urbanos e rurais, e associado a cada um deles, por meio do banco de dados, informações sobre área $\left(\mathrm{m}^{2}\right)$, valor venal, proprietário, data de aquisição, endereço, situação financeira (adimplente ou inadimplente), pode gerar um aumento considerável na arrecadação do IPTU, possibilitando em pouco tempo pagar o sistema implantado. Um exemplo simples pode ser dado pelo censo imobiliário realizado na cidade de Tupã (SP), que possui 64 mil habitantes. De Acordo com Montanha e Doretto (2008), dos 22.771 imóveis com área construída declarados, o confronto de dados da primeira etapa do SIG, detectaramse cerca de 12 mil imóveis com alguma inconsistência, correspondendo a um total de 53\% de irregularidades em relação ao total de imóveis com área construída declarada no município. Para Zero e Pinhata (2008), na cidade de Vinhedo (SP), com 62 mil habitantes, o aumento nas áreas edificadas foi de 43,85\% para o lançamento no IPTU de 2007. Parte desse valor (30\%) já foi implementada ao IPTU de 2006; o aumento na arrecadação foi de R\$ 2 milhões. Se acontecer a reavaliação do terreno e construção de novos parâmetros com o recadastramento pelo Boletim de Cadastros de Imóveis, o próprio morador pode se beneficiar com avaliação do valor de seu imóvel.

O quarto uso do geoprocessamento é encontrado na área da saúde pública. Ulysséa Neto e colaboradores (2000), autores da pesquisa "Uso de SIG na determinação da acessibilidade a serviços de saúde em áreas urbanas", demonstram a utilização do SIG no monitoramento da oferta de serviços de saúde, mapeando a distribuição espacial da população (demanda) e a localização dos pontos de oferta de serviços de saúde, determinando as áreas mais carentes mediante o cálculo de índices de acessibilidade. Na cidade de Meteora, um tipo de geoprocessamento na área saúde já é utilizado. O sistema TabWin, do Ministério da Saúde (Datasus), possui ferramentas para tabular os bancos de dados produzidos pelo SUS, importar dados provenientes de outros sistemas, integrar dados, criar indicadores, gerar gráficos e cartogramas, e permite usar os principais sistemas de informação em saúde: Sistema de Informação sobre Mortalidade (SIM); Sistema de Informação sobre Nascido Vivo (Sinasc); Sistema de Informação sobre Agravos de Notificação (Sinan); Sistema de Informação Hospitalar (SIH); Sistema de Informação Ambulatorial (SIA) e Sistema de Informação da Atenção Básica (Siab). Esse mapeamento das demandas era gerado por áreas de especialidades e não geograficamente. 
Um mapeamento dessas demandas de problemas de saúde pode apontar problemas em outras áreas como saneamento, epidemiologia, educação preventiva e alimentação, por exemplo. Esses levantamentos, articulados pelos agentes comunitários de saúde e com a contribuição da população, podem atingir a prevenção básica de saúde, em ação com as ESFs (Estratégia Saúde da Família) e futuras medidas da prefeitura para: elaborar diagnósticos da situação de saúde e das condições de vida, a identificação de situações-problema e a elaboração de propostas de intervenção.

No setor segurança, Meteora pode contar com outra utilidade do sistema. O combate à criminalidade se torna mais rápido e eficiente quando se pode visualizar através de mapeamentos as áreas de risco, de fuga e incidências de crimes. O Projeto do Sistema de Monitoramento Eletrônico (2008) — "Implantação de rede sem Fio Outdoor com tecnologia Mesh no município de Meteora para cobertura de Pontos de Monitoramento Urbano" - , além das características técnicas, oferece suas justificativas e objetivos de implantação. O projeto promete potencializar as ações da Polícia Militar e a partir das câmeras de vigilância aumentar as ações de prevenção e repressão ao crime e ao mesmo tempo diminuir o medo do crime monitorando logradouros públicos, tendo como princípios ativos a inibição da ação delituosa, o flagrante em tempo real e a identificação do infrator.

Para o turismo, Nodari e colaboradores (2006) analisam que a aplicação do SIG em uma região de potencial turístico subsidiaria o gerenciamento e a disponibilização de informações rápidas e precisas para comunidade e órgãos afins. Atualizar informações espacialmente georreferenciadas pode trazer benefícios como um melhor planejamento e expansão de novas áreas, e das condições turísticas da região, elaborando mapas de acordo com a necessidade do turista. O Instituto Ekko Brasil (2009:1), com apoio do Governo do Estado de Santa Catarina, apresenta o "Projeto Viver Natureza do Rio", que tem o objetivo de aplicar o chamado "Turismo Responsável" nas áreas da bacia hidrográfica do rio Itajaí-Açu e vem tomando a cena das novas opções de turismo, tendo como prioridade a sustentabilidade socioambiental e recentemente o uso de geotecnologias de mapeamento (mapas temáticos e um banco de dados georreferenciados na internet).

A agricultura também oferece o desafio do geoprocessamento para um gestor municipal, sendo usado para a visualização das transformações ocorridas no espaço rural, agrícola, florestal e na gestão ambiental. Atualmente, na região do Alto Vale do Itajaí existem cadastrados 23 mil produtores rurais ativos em aproximadamente 40 mil propriedades rurais, de acordo com Amavi (2007). Segundo a pesquisa de Giotto e Salbego (2004), as ferramentas das geotecnologias são uma arma poderosa para o produtor rural conhecer melhor sua realidade e suas possibilidades, e para os servidores da prefeitura realizarem um plano de desenvolvimento integrado no município. Podendo oferecer ao agricultor um planejamento de transporte, escoamento da produção agrícola, indicadores socioambientais e geográficos, mapas temáticos, análise da vocação turística, controle de safras, manutenção de estradas e uso do solo, gestão de bacias hidrográficas e tratamento de curvas de nível para plantio, detecção de pragas, planejamento de investimentos e destinação de ajuda da prefeitura dependendo da demanda. 
Saúde pública, turismo, planejamento do espaço urbano e rural, controle de cheias, segurança e várias outras aplicações que o geoprocessamento pode realizar. Porém, sem antes esquecer dos benefícios de gestão que esse dispositivo pode oferecer, podemos olhar sob a ótica crítica algumas dessas utilidades e engrenagens.

\section{Análise dos resultados}

\subsection{A bússola do saber}

A cidade de Meteora precisou passar por um recadastramento de imóveis, defasado há quase 20 anos, durante o processo de implantação do geoprocessamento. Esse processo de cadastramento imobiliário ou recadastramento das informações relativas às edificações da cidade teve um trâmite de intervenção social muito delicado. Podemos ter como exemplo o Censo do Instituto Brasileiro de Geografia e Estatística (IBGE), ${ }^{2}$ com levantamentos semelhantes da população. Ele existe desde o ano de 1961 e está enraizado como conduta proposta pelo Estado e aceita pela população ao fornecer informações estatísticas da sua realidade para fins de avaliação numérica qualitativa da população brasileira. Neste caso, o geoprocessamento, além das informações genéricas, possibilita criar a identificação nominal de pessoas e lugares em um sistema como: nome, endereço, condição cadastral entre outras informações de serviços, fluxos e consumos, e, além desses dados técnicos, propostas qualitativas de elementos socioeconômicos. Diante dessas informações, seria possível, então, "descobrir" dados estratégicos, econômicos e pessoais da população sob a justificativa de melhorar a gestão, o planejamento e a integração dessas informações para o governo municipal? Se o censo realizado pelo IBGE possui uma lei que dispõe sobre obrigatoriedade e sigilo das informações coletadas, existe uma mesma lei em relação a esse protocolo de cooperação? Qual o limite de intimidade das informações que podem ser qualificadas como aptas a manter sigilo? Quais os limites éticos, políticos e estratégicos das informações coletadas?

Antes de analisar a parte gráfica, tivemos acesso ao modelo de Boletim de Cadastro Imobiliário Urbano de Meteora, que é alimentado constantemente com dados socioeconômicos para atender ao caráter multifinalitário da tecnologia implantada pelo município, ponto de partida de outras camadas específicas de coleta. Junto ao Boletim, o Projeto de Cooperação (2007:6) prevê outros tipos de informações levantadas, como fotos da fachada de cada unidade edificada, seja ela do tipo residencial, comercial ou industrial, e dados úteis para atender à demanda do cálculo do IPTU, o que aponta para informações muito além dessas, que, em primeiro plano, são a base para o geoprocessamento.

\footnotetext{
${ }^{2}$ A legislação vigente, modificada pela Lei no 5.878 de 11 de maio de 1978, dispõe sobre a obrigatoriedade e sigilo das informações coletadas pelo IBGE, as quais se destinam, exclusivamente, a fins estatísticos e não poderão ser objeto de certidão e nem terão eficácia jurídica como meio de prova.
} 
Ao aliar a qualidade das informações com a proximidade e intimidade delas, a temática da privacidade é trazida ao proscênio mediante novas relações constituídas entre as pessoas e as ferramentas tecnológicas, dispositivos de geolocalização e produção de conteúdo usando como suporte o discurso em defesa da vigilância. Nesse sentido, é necessário analisar que informações são captadas por essas ferramentas, que tipo de mecanismo alimenta o sistema que expõe dados populacionais e quais as condições de extrair saberes úteis para as gestões das cidades.

Isso porque muitos investidores têm usado os dados do geoprocessamento para articular planos de negócios quase infalíveis ao montar suas empresas, cruzando estatísticas de perfis de consumidores, circulação de clientes e demandas de consumo. Para Melo (2003), o nome dado a essa tática chama-se geomarketing, que permite às empresas identificar com bastante precisão os locais de maior potencial de consumo de um produto, com informações de mercado, de vendas ou de marketing com bases de dados geográficas, permitindo a análise e a visualização em mapas digitais do comportamento das variáveis em estudo. É possível determinar a localização dos utilizadores (clientes) na escala do país, cidade, rua, ou a partir do ponto da empresa (por exemplo, todos os clientes num raio de $5 \mathrm{~km}$ a partir dela), podendo fazer buscas pelas tendências de consumo e hábitos dos consumidores, propiciando uma gestão qualificada da distribuição, da publicidade e dos clientes. A compatibilidade com as prerrogativas do marketing tradicional é clara, fazendo a adaptação da oferta às características de uma dada zona/segmento de mercado ou da área de influência de um determinado ponto de venda; o preço, consoante a estratégia de vendas para uma dada zona/segmento, possibilitando aumentar quota de mercado ou a rentabilidade; distribuição, visualizando as possibilidades de crescimento em função do grau de atratividade; infraestrutura dos pontos de venda em função da distribuição geográfica dos clientes e concorrência, e a otimização de rotas de visita a clientes; e, na comunicação, reduzindo os custos e aumentando a eficiência de uma campanha publicitária através de publicidade direcionada e adaptada a uma dada zona/segmento.

Para Lopes e Silva (2008:1) “(...) um dos mais relevantes fatos da política contemporânea pode ser considerado, paradoxalmente, um fato não político: a popularização do marketing eleitoral". O SIG pode tanto servir para gerar argumentos e conhecimento para ser usado em campanhas políticas, como ser um instrumento de marketing político, tendo seis linhas de implementação: inventariar problemas e prioridades da cidade (gestão do município); direcionar publicidade, outdoors, espaços de comício para áreas mais populosas e com maior fluxo de pessoas; otimização de rotas dando o máximo de visibilidade e mínimo gasto de tempo; análise de tendências políticas buscando a representação espacial dos eleitores e possíveis votos; análise sociodemográfica caracterizando a população em aspectos como idade e renda para adequar o discurso ao universo que se pretende atingir; e a integração de estudos de opinião como componente para validar áreas prioritárias para a campanha.

As perguntas que surgem com o processo de mapeamento de informações e o questionamento de que seriam elas privilegiadas estão ligados ao fator risco. Mesmo entendendo os benefícios voltados às cidades com a realização de levantamentos geográficos e populacionais, 
auxiliando os serviços de correios, as concessionárias de serviços, os distribuidores e entregadores que chegam a nossas casas, geram dúvidas sobre o real impacto dessa ferramenta, de que forma ela promoveria a melhoria na eficiência das políticas públicas. O que é problematizado é a falta de critérios e a pouca discussão de um tipo de tecnologia e uso dela, justo porque tem a ver com a intimidade das informações da população. Levanta-se em análise a destinação feita das informações de cada cidadão e que pode ser coletada, comercializada e levada a um uso impróprio ou não legitimado pelos contratos, termos e protocolos.

Ficam nesse preâmbulo discussões que se estendem: sobre a facilidade e sutileza com que o geoprocessamento penetra como verdade tecnológica no núcleo das populações para ceder informações íntimas; sobre o discurso legal de autorização (Estatuto das Cidades e Plano Diretor), que funciona de gatilho legal para implantar um SIG; sobre a qualidade somada à profundidade, igual à intensidade das informações e ao impacto de verdade que se corporifica; sobre qual o limite de intimidade alcançado pelo instrumento de georreferenciamento; sobre os novos modelos de censo usados no Brasil, que atingem o nível dos costumes e hábitos das populações, porém sob resguardo de sigilo legal; sobre a disposição das informações de quem tem acesso, se ela é restrita e será divulgada em partes ou em forma de estatística ampla; sobre com quem ficam as informações da prefeitura, será disposta por níveis de hierarquia dentro do organograma do órgão público, por local de poder ou por especialistas (técnico, médico, prefeito); e sobre que tipo de verdade gerarão as informações por documentos assinados por técnicos, respaldados por empresas, aplicados pela prefeitura, provenientes do resultado dessa tecnologia biopolítica.

Isso acontece porque o geoprocessamento é constituído em sua estrutura por dados estatísticos, carregando junto a si a representação de uma ciência que emergiu em nossa cultura como critério e evidência de verdade exata. O geoprocessamento pode ser avaliado da mesma maneira em suas peças de montagem, pois ele produz saber e cálculos também por meio de um modelo estatístico. A "geoestatística", ou a "aritmética política", ou ainda poderíamos falar de uma "bioestatística", como saber produzido, tem funções estratégicas de gestão das populações e de manutenção do próprio modo de governar, fazendo a interpolação ${ }^{3}$ entre teoria gráfica e álgebra matricial. Quando fenômenos são medidos, a observação desses métodos dita a precisão de qualquer análise posterior, que é determinada a partir da escala e da distribuição de recolha de dados.

No próprio Protocolo de Cooperação (2007), é critério de escolha do projeto que a empresa disponha de um sistema que elimine ao máximo o fator pessoal, oferecendo menor probabilidade de erro, apresentando um bom nível de precisão e estabelecendo equidade de tratamento e a justiça fiscal. Essa precisão esperada pela qualidade dos dados coletados é a propaganda maior de um produto com a marca da "ciência", pois, antes de tudo, o objetivo é a produção de uma verdade válida, mesmo que seja uma mentira maquiada por cálculos.

\footnotetext{
${ }^{3}$ Interpolação é o processo pelo qual uma superfície é criada, geralmente uma varredura de dados, mediante a introdução dos dados coletados em um número dos pontos de amostra.
} 
Um possível governo da ciência, ou melhor, o uso do saber científico para exercer poder no governo público por meio de discursos alicerçados sobre a base método-epistemológica como critério de verdades irrefutáveis é a possibilidade apresentada. "Há regiões onde esses efeitos de verdade são perfeitamente codificados, onde o procedimento pelos quais se pode chegar a enunciar as verdades são conhecidos previamente, regulados. São, em geral, os domínios científicos. No caso das matemáticas, é absoluto" (Foucault, 2006:232-233).

Para Foucault (1999), não importa se a estatística é considerada ciência ou não, quais seus critérios de construção de uma base de saber científica, mas sim como os jogos de poder utilizam a ciência como instrumento de guerra para produzir e sustentar discursos de verdade e produzir efeitos sobre as pessoas. "E depois, afora as ciências, têm-se também os efeitos de verdade ligados ao sistema de informações: quando alguém, um locutor de rádio ou de televisão, lhe anuncia alguma coisa, o senhor acredita ou não acredita, mas isso se põe a funcionar na cabeça de milhares de pessoas como verdade, unicamente porque foi pronunciado daquela maneira, naquele tom, por aquela pessoa, naquela hora" (Foucault, 2006:232-233). Como essas verdades são usadas na conjuntura política da aprovação de obras, planejamento e uso de dinheiro no espaço governamental, como o uso dos resultados do geoprocessamento pode dar rumo às decisões do governo das populações que regem a vida das pessoas na comunidade estudada, como um instrumento que era antes totalmente técnico e prático dando vistas às guerras, ou tão somente aos tributos e ao recrutamento, pode agora ter a possibilidade de gerar dados para legislar e administrar inúmeros aspectos da esfera pública e privada?

Se existe uma política de verdade onde, de acordo com Senra (2005), os discursos perdem as letras e ganham os números e a apreensão desses números na tomada de decisão se dá mais pela garantia de se utilizá-los, muito menos de bem usá-los, esse amparo racional das ciências e a sofisticação instrumental tecnológica de um SIG podem gerar decisões muito mais pessoais do que comprovadas. Não se trata de um risco em potencial, mas de uma evidência circunstancial, de instância técnico-científica para uma técnico-política.

Essa é a relação clara entre o saber e o poder, pois o mesmo saber científico que produz um domínio para a economia faz com que o dispositivo de geoprocessamento condense na mesma receita uma rede de vários domínios de saber reconhecidos cientificamente e interpolados entre si (geografia, estatística, administração, engenharia, economia), agindo por um tipo de prática de poder muito mais densa do que a fantasia de uma promessa de vontade política. O "governo", nesse contexto, adquire então o sentido exato de "arte de exercer o poder na forma (...) da economia" (Foucault, 2008:127).

\subsection{Circulação do poder e o regime da governamentalidade}

Historicamente, dois elementos, a polícia e a estatística, tiveram o papel que hoje, em conjunto, desempenha-se através da geotecnologia de um SIG. Foucault (2008) descreve que era a própria polícia que articulava a fabricação das estatísticas do Estado. A Razão do Estado, que era o racionalismo do aparato estatal, foi um dispositivo de equilíbrio onde a Sociedade da 
Segurança buscou sua sustentação, a polícia, a manutenção das suas forças (como a "inteira arte de governar"), e a estatística, o objetivo de medir, conhecer, prever e manter essas forças visíveis.

É necessário, portanto um princípio de decifração das forças constitutivas de um Estado. É necessário saber, de cada Estado, do seu e dos outros, qual a população, qual o exército, quais os recursos naturais, qual a produção, qual o comércio, qual a circulação monetária — todos estes elementos que são efetivamente dados por essa ciência, ou antes, por esse domínio de conhecimento, (...) a estatística (Foucault, 2008:424).

No caso do geoprocessamento, a relação entre o saber e o poder se estende em um grau de inteligibilidade e maximização do exercício de poder por meio de uma governamentalidade do conhecimento (pelo que faz saber com as informações coletadas), científica (qualidade técnica do que sabe e legitimidade de quem sabe) e do território (quadrantes exatos geográficos com uma rede de saber sobre os mapas). A qualidade da quantificação e qualificação inteligente dos mapas e banco de dados pode oferecer um controle dirigível sobre os dados agregados e consequente domínio sobre os fluxos (deslocamentos) da população.

Essa construção de uma prática de governamentalidade e economia de poder não é nova, pois esses fatores indagam como os problemas específicos da vida e da população foram postos no interior de uma tecnologia de governo desde o século XVIII e de que forma podem ser explicados agora, por um dispositivo biopolítico, com técnicas eficientes que prometem resolver de forma calculada as necessidades de uma população. A nova camada que se sedimenta pós-Razão do Estado aparenta carregar junto de si as técnicas que fizeram do governo e dos dispositivos de segurança um novo plano gestor voltado agora para ações biopolíticas à população. Essas características lançaram a "economia política" como o modelo de administrar as populações, superando o projeto exaustivo da polícia do século XVII, constituindo com isso quatro elementos dinâmicos: prática econômica, gestão da população, direito e respeito às liberdades.

Foucault (2008) traz uma grande discussão sobre os dispositivos, cálculos e as táticas do Estado que fizeram emergir regimes de governamentalidade, e que fizeram da política cada vez mais biopolítica, dado que o governo da população corresponde à inserção das séries e eventos biológicos que definem a espécie humana numa estratégia geral de poder.

Todos esses fatores inquirem como os problemas específicos da vida e da população foram postos no interior de uma tecnologia de governo desde o século XVIII e de que forma podem ser explicados agora, por um dispositivo com técnicas eficientes que prometem resolver de forma calculada as necessidades de uma população. População essa, como um grupo organizado de indivíduos vivos, que aceitou como forma e objeto de governo essas novas práticas para "auxiliá-la", através das tecnologias da informação, como o geoprocessamento. Foucault (2004:192) compreende que não estamos tão somente sobre o regime da polícia ou da governamentalidade, mas indiciados na "(...) maneira como se conduz a conduta dos homens". 
De forma concreta, esses dispositivos de conduta se desdobram em plataformas menores e constituem-se em técnicas de gestão; seja do controle da circulação de pessoas, da vigilância de intimidades ou da intimidação de subjetividades, eles subsidiam o geoprocessamento com informações. Um exemplo disso são as câmeras de vigilância que se estendem sobre os fluxos de pessoas e produtos em uma cidade, desdobram-se como base discursiva para o argumento da segurança e, enquanto tecnologia política, permitem agir como regimes de luz e de enunciação próprios da atualidade. Um novo desdobramento de visibilidade, uma clivagem desses regimes de enunciação e novos mecanismos de funcionamento do poder. Instalado em locais públicos, é quase imperceptível e, por não focar celas individuais, como na sociedade disciplinar, a forma de coibir as pessoas nas vias seria pela autovigilância de suas próprias condutas. O objetivo continua sendo o anonimato, porém invisível ao observado, para vigiar e identificar os fatos e os fenômenos criminais que possam ocorrer. Se a criminalidade impuser novas formas e regras a serem pagas pela população, em último plano, não seria algo muito distante transformar ruas, praças, ônibus e lojas em um grande cárcere, onde todos sejam suspeitos de crimes que ainda não ocorreram e estejam alertas sobre seus pensamentos, palavras e ações expressas pelas vias públicas. "A vigilância por meio de câmeras de vídeo transforma os espaços públicos das cidades em celas de uma imensa prisão. (...) Aos olhos da autoridade - e talvez ela tenha razão - nada mais é semelhante a um terrorista do que o homem comum" (Agamben, 2006:48).

Existe aí um sentido, uma rede que se forma pela vigilância, pelo mapeamento e geoprocessamento, ao tornar visíveis pelas fotos de satélite sua casa, sua rua, seus lugares de circulação; ao tornar registrado seu espaço de deslocamento através de GPS, registros biométricos, cartões de crédito, celulares e ao serem os cidadãos filmados instantânea e continuamente por câmeras de vigilância. O cidadão pode se tornar um instrumento por onde se amplifica a visibilidade (zoom, câmera lenta, replay) de toda uma população, que se torna conhecida, vulnerável e passível de ter seus passos mapeados em uma relação de visibilidade, poder, conhecimento, subjetivação e, principalmente, do registro de sua mobilidade de fluxos e sua regulação.

Essas considerações tecidas em relação aos sistemas de monitoramento eletrônico permitem considerar, para além da Sociedade do Controle de Deleuze (1992), a percepção da Sociedade da Segurança de Foucault (2008), quando pensamos no controle dos fluxos. Para tanto, em outra ordem de práticas, o processo de implantação do geoprocessamento em Meteora gera uma análise sobre o controle das circulações mediante o estabelecimento de um novo sistema viário e o controle sobre as áreas de exploração imobiliária por meio da instituição de um plano diretor.

Essas táticas maximizam o controle da gestão do município. Cria-se um instrumento regulador dos espaços e circulação. Pode-se decidir por quais vias vai seguir o desenvolvimento da cidade, quais áreas vão ser mais valorizadas, quais as áreas onde se pode construir, e de todas as formas é possível exercer uma gestão biopolítica através da produção de um discurso de verdade que é a de um código de conduta de habitabilidade, segurança, conforto ambiental, convívio comunitário, ocupação e socioeconômico. 


\subsection{Biopolíticas e efeitos de subjetividade}

Não há como fazer gestão das políticas públicas sem considerar que existe o exercício administrativo sobre a vida humana. Foucault, que faleceu em 1984, não pôde descortinar a compreensão desses dispositivos, nem dos sistemas de segurança informatizados do século XXI, porém há a possibilidade de explorar e de avaliar, neste caso, um tipo de segregação ou exclusão em uma mecânica não muito diferente das prisões.

[No] final do século XVIII, a sociedade instaurou um modo de poder que não se fundamentava sobre a exclusão - é ainda o termo que se emprega -, mas sobre a inclusão no interior de um sistema no qual cada um devia ser localizado, vigiado, observado noite e dia, no qual cada um devia ser acorrentado a sua própria identidade (Foucault, 2006:255).

Como alerta Foucault (2006:181), nos encontramos virtualmente na presença de um campo de concentração quando é criada uma estrutura e agenciado um dispositivo, independentemente da natureza dos crimes que aí são cometidos e qualquer que seja a sua denominação ou topografia específica.

Observa-se que as pessoas precisam sentir uma sensação, mesmo que imaginária, de estar "incluídas" num sistema de regulação que elas mesmas exigem ter para sua própria segurança. Somente depois de estarem "vestidos" de discursos de modernidade, os sistemas atuais de vigilância, segundo Araújo e colaboradores (2008), fazem com que o sujeito seja formado pela internalização do olhar externo constitutivo e diluído pelo olhar do outro, no estado de visibilidade permanente e consciente ao "saber-se observado", mas "saber-se cuidado". O efeito de "inclusão" espacial combinada com a vigilância pode até regular os passos de quem não precisaria ser vigiado, porém, como funciona esse dispositivo que percorre a intimidade do sujeito e mesmo assim ele o requer? Foucault (1979) abre o argumento: “(...) onde há poder ali existe resistência". ${ }^{4}$ Para Araújo e colaboradores (2008), a forma da vigilância atual e o jeito com que se efetua o poder são tão discretos e sutis em função das novas tecnologias, que a eficiência, extensão e intrusão desse atravessamento de poder/saber sobre o sujeito são quase que imperceptíveis.

Os computadores se tornarão tão pequenos que serão invisíveis. Vão estar entre todas as partes e ao mesmo tempo nenhuma, e serão tão poderosos que vão desaparecer da vista. Pensamos nos carros mais modernos, equipados com dispositivos silenciosos acionados por pequenos computadores de que não somos conscientes (levanta vidros, calefação etc.). (...) Longe de ser um problema futuro, essa invisibilidade já está entre nós (Deleuze apud Giorgi e Rodríguez, 2007:164).

\footnotetext{
4 "As relações de poder suscitam necessariamente, apelam a cada instante, abrem a possibilidade a uma resistência, e é porque há possibilidade de resistência e resistência real que o poder daquele que domina tenta se manter com tanto mais força, tanto mais astúcia quanto maior for a resistência" (Foucault, 2006:232).
} 
As práticas exercidas por agressividade, segundo Foucault (1995), não são formas de poder, mas sim de violência. O poder está numa estrutura de ações que induz, incita, seduz, facilita ou dificulta e, no extremo, constrange, pois é sempre um conjunto de ações sobre outras ações. Esse poder sutil é tão fino que no caso da vigilância, a invasão de privacidade tão cotidiana faz muitas vezes com que o próprio sujeito peça para ser vigiado, ser policiado e ser percebido. Quanto mais as práticas de poder chamam atenção, ameaçam e reprimem, mais elas causam resistência.

(...) não se trata de obter a obediência dos súditos em relação à vontade do soberano, mas atuar sobre coisas aparentemente distantes da população, mas que se sabe, por cálculo, análise e reflexão, que podem efetivamente atuar sobre a população. É essa naturalidade penetrável da população que, a meu ver, faz que tenhamos aqui uma mutação importantíssima na organização e na racionalização dos métodos de poder (Foucault, 2008:94).

Pode-se então se falar de dois extremos, a penetrabilidade e a resistência ao dispositivo. Foucault (2008) lembra que os primeiros teóricos da população sabiam que ela era formada de diversidade, indivíduos pensando e vivendo diferente uns dos outros, sem possibilidades de previsão. Mas desde o século XVIII era de senso entre esses teóricos um motor de ação da população, o desejo. Foucault (1985) já havia em outros momentos feito referência ao desejo circulando no interior das técnicas de poder e de governo, mas ele se refere agora à sutil naturalidade do desejo marcado na população e flexível a técnicas governamentais. Flexível ao deixar agir, ao ser conquistado pelas novidades e tecnologias, gerando um interesse geral da população, um jogo espontâneo levado pelo desejo. "Produção do interesse coletivo pelo jogo do desejo: é o que marca ao mesmo tempo a naturalidade da população e a artificialidade possível dos meios criados para geri-la" (Foucault, 1985:95). A gestão das populações através da naturalidade do desejo e a produção artificial e espontânea de interesse transformam, desde o século XVIII, a população em público-alvo a ser encantado. São as pessoas como espécie humana (biológica), considerando o ponto de vista de sua existência em opiniões, comportamentos, hábitos, exigências, preconceitos e a necessidade de conquista, dizendo sim ao desejo para poder governá-lo.

Quando Foucault (2008) descreve que o que se governa são as pessoas, os indivíduos, as coletividades e as condições de sobrevivência dentro de um território, ele se refere de forma concreta sobre o governo das ações, das atitudes, dos comportamentos e das condutas que guiam essas pessoas. "Possibilidade de ação sobre a ação dos outros" (Foucault, 1995:247). A forma de intervenção biopolítica obtida a partir de um SIG tem um nível de resistência reduzido pelos vários elementos discursivos estatísticos, tecnológicos, científicos, sociais, políticos, econômicos diluídos pela própria mecânica de poder investida. As condições de possibilidade que permitiram esses discursos emergir os legitimam e permitem a todas as ações posteriores serem aplicadas de forma justificada. Elas permitem a liberdade ao sujeito e se o dispositivo “(...) encontra uma resistência, a única escolha é tentar reduzi-la. [E o objetivo dele] não é uma exclusividade do uso da violência mais do que da aquisição dos consentimentos; (...) o 
exercício de poder pode perfeitamente suscitar tanta aceitação quanto se queira" (Foucault, 1995:243).

São essas aceitações, consentimentos e uma resistência silenciosa que fazem do dispositivo geoprocessamento uma prática biopolítica de governo municipal potente, seja por seu caráter positivo, pois o poder é produtivo mediante técnicas de individualização e de processos de totalização, seja para manter atenção e contravigilância, assim como foi feito por centenas de anos pela filosofia no papel de vigiar os excessivos poderes da racionalidade política.

\section{Considerações finais: dispositivo biopolítico e geopolítico}

Para Foucault (1999), os últimos séculos tiveram o uso da própria sociedade como instrumento de ataque para guerras de raças, reinos, povos e religiões. A inscrição mapeada do território foi a garantia de domínio da população e a estratégia política foi flexionar o saber para manutenção do poder. Desde o século XVI, quando Maquiavel escrevia suas instruções para o príncipe se manter alerta ou dominar outros territórios, pode-se perceber que a guerra era um fator de decisão dos rumos dos governos. Com advento das nações, o mundo convergiu em defesa da sociedade. As estruturas políticas se constituíram dentro da conjuntura das nações e buscaram uma nova forma de ação dentro do território, que era a manutenção e ampliação de suas forças econômicas. As guerras mudaram seu foco para lutas econômicas, políticas e pelo Estado. O caminho viável foi gerar inteligência na gestão do próprio território e população. "O que vai constituir o essencial da função e do papel histórico da nação não será exercer sobre as outras nações uma relação de dominação; será diferente; será administrar a si mesma, gerir, governar, assegurar, por si, a constituição e o fundamento da figura e do poder estatais. Não dominação, mas estatização" (Foucault, 1999:267).

Após o século XVIII, com o advento da democracia e da eleição direta de governantes pelo povo, o foco de ampliar e cuidar do território mudou para a eficiência na gestão das biopolíticas para governar pelas pessoas e não mais para o soberano, a política geográfica dando espaço para a gestão biológica da vida humana. Nesse impulso de governo, os instrumentos, tecnologias e técnicas de governo foram se potencializando. O foco da conquista de outros territórios se voltou para a amplificação do conhecimento do seu próprio território e de suas riquezas, e a administração se voltou para políticas de gestão da população para fazer viver, para aumentar o número de pessoas produtivas, para direcionar as pessoas não mais para o treinamento belicoso, mas para o treinamento de fortalecimento da saúde para manutenção da economia.

A formatação do dispositivo de geoprocessamento nesse contexto é a conclusão de um eficiente controle sobre as potencialidades de um determinado território e na gestão de mecanismos que atuam sobre a população. É quando podemos conhecer o espaço por onde os fluxos da economia, dos interesses, dos jogos e da transformação não se confundem mais com o simples deslocamento das pessoas e a aplicação das políticas públicas. 


\section{Referências}

AEAVI. Plano viário estrutural: segunda etapa do estudo da estrutura viária de Meteora. Plano de Circulação de Tráfego Central. Volume B. dez. 2005. Disponível em: <www.riodosul.sc.gov.br/ portal/downloads/transito>. Acesso em: 6 mar. 2008.

AGAMBEN, Giorgio. O que é um dispositivo? Outra travessia. 5. ed. Florianópolis: s.n., 2005.

AGAMBEN, Giorgio. Il filosofo e il cellulare. La Repubblica, 4 nov. 2006. Disponível em: <www. ricerca.repubblica.it/repubblica/archivio/repubblica/2006/11/04/il-filosofo-il-cellu lare.html>. Acesso em: 5 mar. 2009.

AMAVI. Revista AMAVI 40 anos. 2007. Disponível em: <www.amavi.org.br/amavi40anos/revista40anos>. Acesso em: 18 mar. 2008.

ARAÚJO, Uajará P. et al. A vigilância do deslocamento. Universidade Federal de Santa Catarina. Florianópolis. v. 8; n. 1, 2006. Disponível em: <producaoonline.org.br/rpo/article/download/30/29>. Acesso em: 21 mar. 2009.

ARONOFF, Stan. Geographical informationsystem: a management perspective. Ottawa: WDL Publications, 1989.

BENTHAM, Jeremy. O panóptico. Organização e tradução de Tomaz Tadeu da Silva. Belo Horizonte: Autêntica, 2000.

CARVALHO, K.; SÁ, L. M. de. Bases de dados espaciais para pluviometria. Estudo de caso: Recife. Florianópolis: Cobrac, 2004.

DELEUZE, Gilles. Conversações: 1972-1990. Rio de Janeiro: Ed. 34, 1992.

FOUCAULT, Michel. Ditos e escritos IV: estratégia, poder-saber. Organização de Manoel Barros da Mota; tradução Vera Lúcia A. Ribeiro. Rio de Janeiro: Forense Universitária, 2006.

FOUCAULT, Michel. Dits et écrits (1954-1969). Paris: Gallimard, 1994a. v. 2.

FOUCAULT, Michel. Dits et écrits (1980-1988). Paris: Gallimard, 1994. v. 4.

FOUCAULT, Michel. Em defesa da sociedade: curso no Collège de France (1975-1976). Tradução de Maria Ermantina Galvão. São Paulo: Martins Fontes, 1999.

FOUCAULT, Michel. História da sexualidade 1: vontade de saber. Tradução de Maria Thereza da Costa Albuquerque; revisão técnica de José Augusto Guilhon Albuquerque. Rio de Janeiro: Graal, 1985.

FOUCAULT, Michel. Microfísica do poder. Organização e tradução de Roberto Machado. 17. ed. Rio de Janeiro: Graal, 1979.

FOUCAULT, Michel. Naissance de la biopolitique. Paris: Gallimard, 2004. 
FOUCAULT, Michel. O sujeito e o poder. In: DREYFUS, H.; RABINOW, P. Michel Foucault: uma trajetória filosófica: para além do estruturalismo e da hermenêutica. Rio de Janeiro: Forense Universitária, 1995. p. 231-249.

FOUCAULT, Michel. Segurança, território e população. Curso no Collège de France (1977-1978). Tradução de Eduardo Brandão. São Paulo: Martins Fontes, 2008.

FOUCAULT, Michel. Vigiar e punir (1970-1975). Petrópolis: Vozes, 1987.

G1. Chuva traz risco de novos deslizamentos em SC. 29 nov. 2008. Disponível em: <www.g1.globo. com/Noticias/Brasil/>. Acesso em: 21 jan. 2009.

GIORGI, Gabriel; RODRÍGUEZ, Fermín (Comp.). Ensayos sobre biopolítica: excesos de vida (Gilles Deleuze/Michel Foucault/Antonio Negri/Slavoj Zizek/Giorgio Agamben). Buenos Aires: Paidós, 2007.

GIOTTO, Enio; SALBEGO, Adriana G. Geoprocessamento aplicado ao diagnóstico e espacialização da infraestrutura viária rural. Florianópolis (SC): Cobrac (Congresso Brasileiro de Cadastro Técnico Multifinalitário - UFSC), 2004.

INSTITUTO EKKO BRASIL. Projeto Viver Natureza do Rio. Apoio do Governo do Estado de Santa Catarina. Apresentação na Câmara de Vereadores de Meteora. s.1.: s.n., 2009.

LOPES, Rui; SILVA, Roberto. Geomarketing eleitoral: aplicação de metodologias e ferramentas de geomarketing em campanha eleitoral municipal. 2008. Disponível em: <www.gismedia.pt>. Acesso em: 29 fev. 2009.

MELO, Tiago E. Uso e aplicação de modelos econômicos em sistemas de informação para geomarketing. Campinas: s.n., 2003.

MONTANHA, Enaldo P.; DORETTO, Silvio. E. Geoprocessamento para controle das políticas públicas. MundoGEO. 2008. Disponível em: <www.mundogeo.com.br/revistas-interna.php?id_noticia $=8089>$. Acesso em: 20 fev. 2008.

NODARI, Luciana D. et al. Aplicação do geoprocessamento como ferramenta de auxílio ao turismo. Florianópolis: Cobrac (Congresso Brasileiro de Cadastro Técnico Multifinalitário - UFSC), 2006.

PRADO FILHO, Kleber. Uma história da governamentalidade. Rio de Janeiro: Achiamé, 2006.

PREFEITURA MUNICIPAL DE METEORA. Relatório da reunião de apresentação do Projeto Tracksourse. Meteora: Auditório Renato Cardoso. Gravado em: 31 out. 2008.

PROJETO SISTEMA DE MONITORAMENTO ELETRÔNICO. Implantação de rede sem fio outdoor com tecnologia Mesh no município de Meteora para cobertura de pontos de monitoramento urbano. Meteora: s.n., 2008.

PROTOCOLO DE COOPERAÇÃO: Sistema de Informações Geográficas da Amavi-Siga. Meteora: Prefeitura Municipal, 2007.

REVISTA CIDADE DO BRASIL. Geoprocessamento: tecnologia tem utilização cada vez maior pelas prefeituras e hoje é essencial para vasta gama de aplicações. 59. ed. mar. 2005. Disponível em: 
$<$ www.cidadesdobrasil.com.br/cgicn/news.cgi?cl=099105100097 100101098114\&arecod=12\& newcod=88>. Acesso em: 25 jul. 2008.

RODRIGUES, Marcos. Geoprocessamento. In: ENCONTRO NACIONAL DE ENGENHEIROS CARTÓGRAFOS, 5., 1988, Presidente Prudente. Anais... Marília; Presidente Prudente: Gráfica da Unesp, 1988. v. 1, p. 144-160.

SENRA, Nelson de C. Informação estatística como objeto de estudo (Uma primeira tentativa de formalização). Data Grama Zero: Revista de Ciência da Informação, v. 6, n. 4, s.p., 5 ago. 2005. Disponível em: <www.acd.ufrj.br/gruporetis/sig/tiki-index.php>. Acesso em: 25 jul. 2008.

STASSUN, Cristian C. S. Dispositivo: fusão de objeto e método de pesquisa em Michel Foucault. Cadernos de Pesquisa Interdisciplinar em Ciências Humanas, v. 11, p. 54-71, 2010.

STASSUN, Cristian C. S. Relatório da reunião de apresentação do projeto Tracksourse na Prefeitura Municipal de Meteora. Meteora: Auditório Renato Cardoso, 2008.

ULYSSÉA NETO, Ismael et al. Uso de SIG na determinação da acessibilidade a serviços de saúde em áreas urbanas. Florianópolis (SC): Cobrac (Congresso Brasileiro de Cadastro Técnico Multifinalitário - UFSC), 2000.

VEIGA-NETO, Alfredo. Coisas do governo... In: RAGO, Margareth; ORLANDI, Luiz B. L.; VEIGANETO, Alfredo (Org.). Imagens de Foucault e Deleuze: ressonâncias nietzschianas. Rio de Janeiro: DP\&A, 2002. p. 13-34.

ZERO, Cileno B.; PINHATA, Milton V. Geoprocessamento na Prefeitura Municipal de Vinhedo: um caso de sucesso. MundoGEO. Disponível em: <www.mundogeo.com.br/revistas-interna.php?id_noticia $=8087>$. Acesso em: $22 \mathrm{dez} .2008$.

Cristian Caê Seemann Stassun é doutorando interdisciplinar de ciências humanas da Universidade Federal de Santa Catarina (UFSC).E-mail: cristianccss@hotmail.com.

Kleber Prado Filho é professor doutor do Programa de Pós-graduação de Psicologia da UFSC. E-mail: kprado@brturbo.com.br. 
